\title{
Implementation of Virtual Training by HR Consultants for IT Companies- Bridging the Gap
}

\author{
${ }^{1}$ Poorani.T, ${ }^{2}$ Dr. Rajeswari.B \\ ${ }^{I}$ Research Scholar,Department of Management Studies, Pondicherry Central University, Pondicherry - 605014. \\ ${ }^{2}$ Asst Professor, Department of Management Studies, Pondicherry Central University, Pondicherry - 605014.
}

\begin{abstract}
Outsourcing of training is considered as a major management challenge in the turbulent environment with respect to the increase in the trends of technology and business needs. Due to this increase in business needs, there is more pressure on the companies to put more efforts on the training and development arena and ensure that they do not become obsolete in the market. And outsourcing on need basis has been broadly accepted as a more cost-effective method for creating or delivering training modules especially for IT companies. Another major challenge of IT industry (especially in India) is Globalization of the employees across other countries. To address the training needs on a global perspective, Virtual Training is a one- stop solution. With the option of Virtual Training available to the employees, that they can enhance their knowledge and cope up with the demands and trends irrespective of the location and time constraint. Many IT companies have started allocating their budgets to enable this option of online based or web-based learning interventions for their employee's skill development. However, there is still a gap prevailing among the consultants with respect to equipping themselves to move towards the Virtual Training delivery model and most of the consultants are still hesitant to move towards Virtual Training and still restricting with the formal classroom delivery mode. Thus, this paper would explore and analyze the 360 degree perspective of Virtual Training, to identify the gaps (difficulty level) in implementing Virtual Trainings (from a consultant's point of view) and to provide solutions to bridge the gap.

From a consultant's point of view, considering that providing 'Virtual Training' is a form of 'service delivery', the methodology adopted would be mapping the service to the elements of 8 P's of service delivery model to identify the gaps. Hence a questionnaire had been designed for the using the 8 P's as the parameters (Product, Price, Place, Promotion, People, Process, Physical evidence and Productivity) and is circulated to the consultants before and after training to identify the difficulties in delivering Virtual Training effectively. The findings were based on the analysis made using the various statistical tools. The solutions/ suggestions are given based on the inferences from the findings.

This paper identifies the various key focus points where the consultants face difficulty and provides viable solutions to rectify the blocks and paves way for the consultants take the leap from the formal training modes to the next era of providing instant learning solutions. Secondly, it would benefit the clients who are experiencing the Virtual Trainings to get a more refined and instant training solutions in a more user friendly approach and tackle the issue of globalization of employees
\end{abstract}

Keywords: Virtual Training, Outsourcing, Consultants, $8 P$ 's of service delivery, IT Companies.

Global Training Outsourcing scenario:

\section{Introduction}

In a study conducted by Hewitt Associates, 94\% said of those surveyed said that they had outsourced one or more HR functions (Gurchiek, 2005). If the organization needs experts and cannot afford to hire or train them, outsourcing may be a solution. Outsourcing and external partnering provide organizations the flexibility to adapt to external changes, the possibility for appropriating outside expertise, the opportunity to reduce overhead costs, and the chance to focus resources on strategic initiatives. (Snell, S. A., Stueber, D. \& Lepak, D. P. (2001).

Earlier research has shown that more than 70 percent of organizations outsourced some aspect of training design or delivery (Buckley. 1996). The growth of outsourcing in the training area has steadily increased over the past decade. As per the training survey report of 2010 about 81 percent of companies expect spending on training outsourcing to increase or remain the same and companies that are outsourcing are for the most part satisfied with their use of external training providers.( Cushing Anderson,2010) 


\section{Virtual Training - a form of service delivery:}

Services can range from financial services provided by the banks to technology services provided by the IT company or hospitality services provided by hotels and restaurants or even a blog where an author provides a service (information presentation, interesting reading etc) to his audience (Arpan Kar,2011). On the grounds of this factor, Virtual Trainings can be considered as a service to the companies. Quality perception is a crucial differentiating factor on services management and for long term sustainability of the same.

\section{Significance of Virtual Training:}

Those companies that are outsourcing training functions primarily to supplement internal resources do so to have training resources available on an as-needed basis and because they believe that training outsourcing is a more cost-effective method of creating or delivering training. (Cushing Anderson, 2010). Secondly, globalization, diversity, information technology, intellectual capital, and the like are at once increasing organizational variation and providing a catalyst for innovative approaches to collaboration and integration. As the pace of change accelerates, it places a premium on organizational flexibility, capability, and rapid response. Firms compete less on products and markets and more on competencies, relationships, and new ideas. (David I Lepak et al.,2005). One single stop solution to address these demands is 'Virtual Training'. In short, Virtual Training helps the associate to meet their training needs based on the slogan: 'Anything, Anytime and Anywhere' which is the most required in our current scenario.

In spite of the several advantages of moving towards Virtual Trainings however most of the Consultants especially in India are hesitant to take the next step and move towards Virtual Trainings. Hence this paper aims at identifying the various areas, where the consultants are finding the difficulty in implementing the Virtual Training and suggests the suitable concentration spots and suggestions for effective implementation of the Virtual Training.

\section{Literature Review}

Hitches in implementing Virtual Training effectively- Identifying the gaps:

There were wholesome reviews about the various myths and hitches that the consultants faced when they want to implement Virtual Trainings. The below are some of the major focus points that helped in identifying the gaps in implementing Virtual Trainings effectively.

Programs that seek to change student attitudes, such as dealing with cultural differences or behavioral training, do not work as well online. Nonetheless, online information may be used effectively as an adjunct to traditional classroom teaching. Similarly, the courses that require students to use physical skills or hands-on experience cannot rely on Virtual Training. (Robert W. Taylor, 2002) Thus this paper analyses the difficulties in implementing Virtual Training for technical and behavioral programs separately.

Bandwidth/browser limitations may restrict instructional methodologies -...If your content relies on a lot of video, audio, or intense graphics, and your audience isn't on a T1 line, Net delivery will only frustrate your learners. Web-based training has high-fixed costs (Gary James,2002) .

Cifuentes (2001) summarizes the major disadvantages of online learning as technical challenges such as technical failure, constraints of e-mail such as sending diagrams or pictures, and the time involved. Taylor (2002) points out that face-to-face interaction is missing, and motivating students to collaborate online can be a time consuming task.

\section{Estimation of the parameters and check points and framing the tool to identify the gaps:}

Academics and marketing practitioners point out those services differ from products; they are intangible, heterogeneous, perishable and inseparable from the service provider. Additional P's have evolved to help create a comprehensive framework for marketing services. Applying the Eight P's in a service business is essential to developing a marketing plan (Scott Smith, Demand Media).

Services marketing are dominated by the 7 Ps of marketing namely Product, Price, Place, Promotion, People, Process and Physical evidence The 8th P is Productivity and Quality. Quality perception is a crucial differentiating factor on services management and for long term sustainability of the same. Business Process Remodeling can lead to major process efficiency improvements which again can impact overall quality as is actually delivered by the firm and is also perceived by the customers / clientele. (Arpan Kar,2011). The various focus points for the 7 P's of service marketing is indicated in the Figure 1 below that was taken as the basis to frame the tool to identify the gaps: 


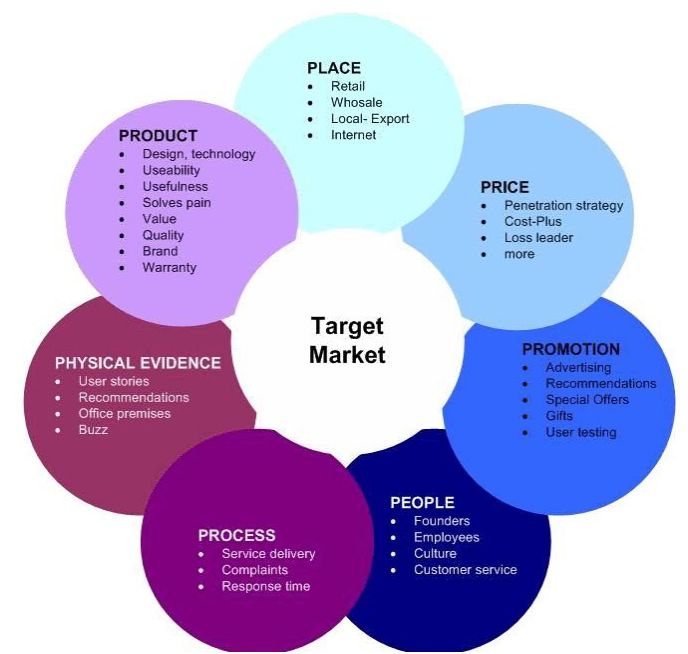

Figure 1: Focus Areas in the 7 P's of service Marketing Model

\section{Methodology}

The aim of this paper is to estimate the difficulty levels in implementing Virtual Training considering the Virtual Training delivery as a mode of service delivery by mapping the same into the 8 P's of effective service delivery model. Thus 31 consulting companies providing Virtual Training services were identified in Chennai for the study and the consultants pertaining to these 31 companies were selected based on simple random sampling making the sample size for the study to be 30. The 8 parameters (Product, Price, Place, Promotion, People, Process, Physical evidence and Productivity) were used as the basis to develop the questionnaire. Two questionnaires were developed: the first questionnaire will focus on the difficulty levels of the 8 parameters before the training and during the training and the second questionnaire will focus on the difficulty levels of the 8 parameters after the training. The first one was circulated to estimate the current scenario and after three months, the second questionnaire was circulated for estimating the difficulties of the post training scenario.

The following explains the nature and description of questions under each of the parameter. For each of the parameters, the various aspects pertaining to pre-training, during training and post training were taken into account to frame the questions.

\section{People:}

In Pre- training we would focus on the difficulties faced in fixing up of the training audience and trainer. In the segment of analyzing the difficulties faced during the training, the difficulty levels in handling the training audience at various levels and adapting to the cultural differences will be focused upon. For estimating the Post- training difficulties faced, the difficulty levels in estimating the Satisfaction of the audience after training was focused upon.

\section{Product:}

In Pre- training we would focus on the difficulties faced in delivering Virtual Training as a packaged service. In the segment of analyzing the difficulties faced during the training, the difficulty levels in delivering the various product category options available were focused upon. For estimating the Post- training difficulties faced, the difficulty levels in estimating the feedback of the course content was analyzed.

Place:

In Pre- training we would focus on the difficulties faced with respect to the location and delivering training as a group or individual level. In the segment of analyzing the difficulties faced during the training, the difficulty levels in delivering a uniform training experience was focused upon. For estimating the Post- training difficulties faced, the difficulty levels in estimating the environment feedback was analyzed.

\section{Process:}

In Pre- training we would focus on the difficulties faced in requirements gathering, content development and checking the pre-requisites of the audience. In the segment of analyzing the difficulties faced during the training, the difficulty with respect to the mode of delivery and keeping up the agenda were focused upon. For estimating the Post- training difficulties faced, the difficulty levels in estimating the individual goals vs training goals synchronization was analyzed. 
Price:

In Pre- training we would focus on the difficulties faced in fixing costs of the various elements of Virtual Training. In the segment of analyzing the difficulties faced during the training, the difficulty levels with respect to the update cost or contingency cost were focused upon. For estimating the Post- training difficulties faced, the difficulty levels in estimating the ROI and profit was analyzed.

Promotion:

In Pre- training we would focus on the difficulties faced in delivering Virtual Training at various levels (organization level, group level and individual level). In the segment of analyzing the difficulties faced during the training, the difficulty levels in creating interest in the audience were focused upon. For estimating the Posttraining difficulties faced, the difficulty levels in estimating the impact of the various promotional offers was analyzed.

\section{Productivity/Quality:}

In Pre- training we would focus on the difficulties faced to estimate the ROI, business impact and alignment to business or organizational need. Also, the validation of course content, instructor and delivery mode with the clients was focused upon. In the segment of analyzing the difficulties faced during the training, the contribution of support tools was focused upon. For estimating the Post- training difficulties faced, the difficulty levels in estimating the learning effectiveness and job impact was analyzed.

\section{Physical evidence:}

In Pre- training we would focus on the difficulties faced in giving a demo before the training. In the segment of analyzing the difficulties faced during the training, the difficulty levels in estimating the comfort level of the participants, getting their attention and interaction with participants were focused upon. For estimating the Post- training difficulties faced, the difficulty levels in estimating the overall training feedback was analyzed.

The first questionnaire was initially circulated to the consultants and the difficulties faced in implementing Virtual Training before and during the training were captured. After 3 months of time, the difficulties faced in the phase of analyzing the post training effectiveness were captured. The rating scale used in the questionnaire is a 5 point scale (1- Easy to implement, 2- Less difficult to implement, 3-Moderately difficult to implement, 4-Very Difficult to implement and 5-Most Difficult to implement). The methodology hence focuses on using the 8 P's (Product, Price, Place, Promotion, People, Process, Physical evidence and Productivity) as the parameters, developing a questionnaire as a tool to analyze the aspects of Virtual Training which includes the various tasks/factors influencing the $8 \mathrm{P}$ 's pre-training and post training. This helps in estimating the gaps prevailing in implementing Virtual Training effectively.

Various statistical tools were used to identify the high impact factors and arrive at a solution to bridge the gaps. The tool considers the implementation of Virtual Trainings for technical and behavioral courses as separate entities based on previous literature reviews. The findings were based on the analysis made by comparing the mean scores of each of the technical and behavioral categories and the corresponding 8 P's of the technical and behavioral categories and uses the Friedman's ranking test for interpreting the high impact factors. Also t- test and ANOVA were used to test some significant hypothesis framed pertaining to estimating the pros and cons of implementing Virtual Training. The solutions/ suggestions are given based on the inferences from the findings.

\section{Analysis And Results}

\section{Frequency Distribution of the various profile indicators:}

Table 1: Represents the distribution of the various profile indicators:

\begin{tabular}{|c|c|c|c|}
\hline Variables & Classification & Frequency & Percent \\
\hline No. of Clients & $<5$ & 2 & 6.5 \\
\hline & 5 to 10 & 8 & 25.8 \\
\hline & 10 to 20 & 15 & 48.4 \\
\hline & 20 to 40 & 4 & 12.9 \\
\hline & $>40$ & 2 & 6.5 \\
\hline Outsourcing & Yes $*$ & 21 & 67.7 \\
\hline & No** & 10 & 32.3 \\
\hline No.of Sectors & 1 & 6 & 19.4 \\
\hline & 2 & 10 & 32.3 \\
\hline & 3 & 8 & 25.8 \\
\hline & 4 & 6 & 19.4 \\
\hline & 5 & 1 & 3.2 \\
\hline No.of branches & 1 & 21 & 67.7 \\
\hline & 2 & 6 & 19.4 \\
\hline & 3 & 4 & 12.9 \\
\hline
\end{tabular}


*implies the consultants are outsourcing

**implies the consultants are not outsourcing.

Result 1: About $48.4 \%$ of the consultants have $10-20$ clients followed by $25.8 \%$ of the consultants having 5 to 10 clients. The least percentage of $6.5 \%$ id shared by consultant having $<5$ clients and $>40$ clients.

Result 2: Majority (67.7\%) of the consultants outsource some form of the training implementation activities like content development or trainers or infrastructure support etc...

Result 3: Majority (80.6\%) of the consultants are into more than one sector (NGO, Manufacturing, Education Etc.) and it is only $19.4 \%$ of the consultants who are focusing on only IT sector

Result 4: Majority (67.7\%) of the consultants have only one branch.

\section{T-tests and Results:}

Table 2: Represents the comparison of means of the technical and behavioral category of Virtual Training to find the level of Significance and correlation between them.

\begin{tabular}{|l|r|r|r|}
\hline Variables & Mean & t-value & Significance \\
\hline Technical & 2.208 & \multirow{2}{*}{4.778} & .000 \\
\hline Behavioral & 2.443 & & .00 \\
\hline
\end{tabular}

Result 5: Results of t- test between implementing virtual programs for technical and behavioral are in Table 2 . It can be seen that the mean value of behavioral category is more than technical category and difference is significant at $5 \%$. Therefore, this indicates that consultants encounter more difficulties while implementing behavioral Virtual Trainings (based on mean 2.44) compared to technical Virtual Trainings implementation.

Table 3: Represents the comparison of means within the 8P's of Technical and behavioral category

\begin{tabular}{|c|c|c|c|}
\hline Variables & Mean & t-value & Significance \\
\hline People-Technical & 2.176 & \multirow[b]{2}{*}{-5.042} & \multirow[b]{2}{*}{0} \\
\hline People-Behavioral & 2.459 & & \\
\hline Product - Technical & 2.11 & \multirow[b]{2}{*}{-3.333} & \multirow[b]{2}{*}{0.002} \\
\hline Product - Behavioral & 2.329 & & \\
\hline Place - Technical & 2.355 & \multirow[b]{2}{*}{-1.592} & \multirow[b]{2}{*}{0.122} \\
\hline Place - Behavioral & 2.441 & & \\
\hline Process - Technical & 2.19 & \multirow[b]{2}{*}{-3.595} & \multirow[b]{2}{*}{0.001} \\
\hline Process-Behavioral & 2.426 & & \\
\hline Price-Technical & 2.294 & \multirow[b]{2}{*}{-3.034} & \multirow[b]{2}{*}{0.005} \\
\hline Price- Behavioral & 2.419 & & \\
\hline Promotion-Technical & 2.215 & \multirow[b]{2}{*}{-3.166} & \multirow[b]{2}{*}{0.004} \\
\hline Promotion-Behavioral & 2.419 & & \\
\hline Productivity-Technical & 2.122 & \multirow[b]{2}{*}{-4.607} & \multirow[b]{2}{*}{0} \\
\hline Productivity -Behavioral & 2.487 & & \\
\hline Physical Evidence -Technical & 2.232 & \multirow[b]{2}{*}{-3.537} & \multirow[b]{2}{*}{0.001} \\
\hline Physical Evidence -Behavioral & 2.555 & & \\
\hline
\end{tabular}

Result 6: From Table 6, it can be seen that the mean value of behavioral category is more than technical category for all the 8 Ps and the difference is significant at 5\% for all 7 P's except the 'Place'. Hence it is evident that implementation of behavioral trainings on a virtual mode has more difficulties during the implementation stages with respect to 7 Ps compared to that of Technical training implementation.

Table 4: Represents the comparison of means of the Pre training and Post training activity difficulties for technical and Behavioral categories

\begin{tabular}{|l|l|l|l|}
\hline Variables & Mean & t-value & Significance \\
\hline Pre Technical Score & 2.210 & \multirow{2}{*}{-0.508} & \multirow{2}{*}{0.615} \\
\cline { 1 - 2 } Post Technical Score & 2.240 & & \multirow{2}{*}{-2.616} \\
\cline { 1 - 2 } Pre Behavioral Score & 2.430 & 0.014 \\
\hline Post Behavioral Score & 2.590 & & \\
\hline
\end{tabular}

Result 7: Results of $t$ test between pre and post training of the consultancy on Technical and Behavioral categories are in Table 4. It can be seen that the mean value of pre -training score for technical is less than posttraining score of technical but this difference is not significant. Therefore it cannot be concluded that consultants face/encounter different levels of difficulties during pre and post trainings for Technical trainings implementation. For behavioral training implementations, this difference is significant at $5 \%$ therefore consultant encounter more difficulties during post training (based on mean of 2.59) than the pre- training 
Table 5: Represents the comparison of means of the Pre training and Post training activity difficulties for 8 P's of Technical and Behavioral categories

\begin{tabular}{|c|c|c|c|c|}
\hline Category & $\begin{array}{r}\text { Variables } \\
\end{array}$ & Mean & t-value & Significance level \\
\hline \multirow{16}{*}{ Technical } & People Pre Training & 2.166 & \multirow{2}{*}{-0.665} & \multirow{2}{*}{0.511} \\
\hline & People Post Training & 2.29 & & \\
\hline & Product Pre training & 2.1613 & \multirow{2}{*}{2.054} & \multirow{2}{*}{.049} \\
\hline & Product Post training & 1.9 & & \\
\hline & Place Pre Training & 2.367 & \multirow{2}{*}{0.52} & \multirow{2}{*}{0.607} \\
\hline & Place Post Training & 2.29 & & \\
\hline & Process Pre Training & 2.179 & \multirow{2}{*}{-0.998} & \multirow{2}{*}{0.326} \\
\hline & Process Post Training & 2.29 & & \\
\hline & Price Pre Training & 2.258 & \multirow{2}{*}{-3.476} & \multirow{2}{*}{.002} \\
\hline & Price Post Training & 2.61 & & \\
\hline & Promotion Pre Training & 2.225 & \multirow{2}{*}{0.343} & \multirow{2}{*}{0.734} \\
\hline & Promotion Post training & 2.194 & & \\
\hline & Productivity Pre Training & $2.12 \mathrm{E}+00$ & \multirow{2}{*}{0.133} & \multirow{2}{*}{0.895} \\
\hline & Productivity Post Training & 2.113 & & \\
\hline & Physical Evidence Pre Training & 2.2339 & \multirow{2}{*}{0.096} & \multirow{2}{*}{0.924} \\
\hline & Physical Evidence Post Training & 2.23 & & \\
\hline \multirow{16}{*}{ Behavioral } & People Pre Training & 2.435 & \multirow{2}{*}{-1.722} & \multirow{2}{*}{0.095} \\
\hline & People Post Training & 2.74 & & \\
\hline & Product Pre training & 2.371 & \multirow{2}{*}{1.826} & \multirow{2}{*}{0.078} \\
\hline & Product Post training & 2.16 & & \\
\hline & Place Pre Training & 2.445 & \multirow{2}{*}{0.173} & \multirow{2}{*}{0.864} \\
\hline & Place Post Training & 2.42 & & \\
\hline & Process Pre Training & 2.385 & \multirow{2}{*}{-2.825} & \multirow{2}{*}{0.008} \\
\hline & Process Post Training & 2.81 & & \\
\hline & Price Pre Training & 2.354 & \multirow{2}{*}{-5.391} & \multirow{2}{*}{.000} \\
\hline & Price Post Training & 3 & & \\
\hline & Promotion Pre Training & 2.483 & \multirow{2}{*}{1.882} & \multirow{2}{*}{0.07} \\
\hline & Promotion Post training & 2.29 & & \\
\hline & Productivity Pre Training & 2.465 & & \\
\hline & Productivity Post Training & 2.565 & -0.678 & 0.503 \\
\hline & Psysical Evidence Pre Training & 2.508 & & \\
\hline & Physical Evidence Post Training & 2.74 & -2.855 & 0.008 \\
\hline
\end{tabular}

Result 8: Results of $t$ test between pre and post training of the consultancy on Technical and Behavioral categories for each of the 8 P's are analyzed in Table 5. It can be seen that the mean value of pre -training score for technical the 'Product' variable is more than post-training score of technical and the difference is significant at $5 \%$ for behavioral trainings. Similarly, that the mean value of post -training score for technical the 'Price' variable is more than pre-training score of technical and the difference is significant at $5 \%$.

Friedman's Ranking Test:

Table 6: Represents the Ranking of the 8 P's with respect to Technical category and Behavioral category of implementing Virtual Trainings.

\begin{tabular}{|c|c|c|c|c|}
\hline Variable & Mean Technical Rank & Mean Behavioral Rank & Chi-Square Value & Level of Significance \\
\hline Place & 5.31 & 4.81 & \multirow{8}{*}{$\begin{array}{l}\text { Technical - } 11.639 \\
\text { Behavioral- } 6.187\end{array}$} & \multirow{8}{*}{$\begin{array}{l}\text { Technical- } 0.113 \\
\text { Behavioral }-0.518\end{array}$} \\
\hline Price & 5.21 & 4.71 & & \\
\hline Physical Evidence & 4.77 & 4.81 & & \\
\hline Process & 4.44 & 4.35 & & \\
\hline Promotion & 4.32 & 4.29 & & \\
\hline People & 4.26 & 4.84 & & \\
\hline Productivity & 3.97 & 4.68 & & \\
\hline Product & 3.73 & 3.61 & & \\
\hline
\end{tabular}

Result 9: There is no significant difference between technical and behavioral categories with respect to the ranking of 8 P's.

Table 7: Represents the individual mean ranking for each of the sub parameters in the tool for Technical and behavioral training category. The overall top 5 attributes with respect to the difficulty level is as follows.

\begin{tabular}{|l|l|l|l|}
\hline Technical & Mean Rank & Behavioral & Mean Rank \\
\hline $\begin{array}{l}\text { In achieving uniform experience among all } \\
\text { participants }\end{array}$ & 25.34 & $\begin{array}{l}\text { In achieving uniform experience among } \\
\text { all participants }\end{array}$ & 26.11 \\
\hline $\begin{array}{l}\text { Incurring cost for updating technology } \\
\text { periodically }\end{array}$ & 22.85 & $\begin{array}{l}\text { In determining the ROI and Profit for the } \\
\text { consultancy }\end{array}$ & 23.82 \\
\hline
\end{tabular}




\begin{tabular}{|l|l|l|l|}
\hline $\begin{array}{l}\text { In determining the ROI and Profit for the } \\
\text { consultancy }\end{array}$ & 22.21 & $\begin{array}{l}\text { Creating interests among participants to } \\
\text { ensure next registration }\end{array}$ & 21.61 \\
\hline $\begin{array}{l}\text { In keeping up the agenda and timing } \\
\text { during delivery of training }\end{array}$ & 21.56 & Getting the attention of the participants & 21.45 \\
\hline $\begin{array}{l}\text { Handling the target audience at various } \\
\text { hierarchical levels }\end{array}$ & 21.1 & $\begin{array}{l}\text { In estimating the overall training } \\
\text { experience and identifying the gaps } \\
\text { pertaining to the same }\end{array}$ & 20.6 \\
\hline
\end{tabular}

Result 10: The above table indicates the ranking of the most difficult areas with respect to the technical and behavioral implementation of Virtual Trainings.

Table 8: Friedman test for various modes of training 1- best and 5-least preferred

\begin{tabular}{|l|l|l|l|}
\hline & Mean Rank & $\begin{array}{l}\text { Chi square } \\
\text { value }\end{array}$ & Level of Significance \\
\hline Video Conference & 2.52 & & \\
\cline { 1 - 2 } Pre- recorded Videos & 2.77 & & \\
\hline Webinars & 2.84 & \\
\cline { 1 - 2 } Live Meetings & 3.39 & \multirow{2}{*}{9.646} & 0.047 \\
\hline e- Learnings & 3.48 & & \\
\hline
\end{tabular}

Result 11: The comparison of the various modes of training using Friedman's ranking is found to satisfy 5\% level of significance and shows that Video Conferencing and Pre-recorded videos are the most preferred virtual modes of delivering training.

\section{One way ANOVA:}

\section{Technical and Behavioral variables Vs Factors:}

Table 9: Represents the comparison of technical and behavioral means with each of the Factor variable namely No. of Branches, No. of clients, No. of sectors and Outsourcing

\begin{tabular}{|c|c|c|c|c|c|}
\hline Variables & Classification & $\begin{array}{c}\text { Technical - Mean } \\
\text { for individual } \\
\text { factor values } \\
\end{array}$ & $\begin{array}{c}\text { Technical - F } \\
\text { Value }\end{array}$ & $\begin{array}{c}\text { Behavioural - Mean } \\
\text { for individual factor } \\
\text { values } \\
\end{array}$ & Behavioural - F Value \\
\hline \multirow[t]{3}{*}{ No. of Clients } & $<5$ & 2.922 & \multirow{3}{*}{$4.157 * * *$} & 2.922 & \multirow{3}{*}{$2.659 *$} \\
\hline & 10 to 20 & 2.021 & & 2.342 & \\
\hline & 20 to 40 & 2.047 & & 2.125 & \\
\hline Outsourcing & No & 2.431 & 2.772 & 10 & 1.784 \\
\hline \multirow[t]{4}{*}{ No.of Sectors } & 1 & 2.49 & \multirow{4}{*}{1.355} & 2.677 & \multirow{4}{*}{1.331} \\
\hline & 2 & 2.156 & & 2.328 & \\
\hline & 3 & 2.258 & & 2.586 & \\
\hline & 4 & 2.104 & & 2.396 & \\
\hline
\end{tabular}

(Level of Significance - '*' implies 10\%, '**' implies 5\% and ' $* * *$ ' implies 1\%)

Result 12: The above table proves that there is a $5 \%$ level of significance with respect to the relation between implementing technical trainings and $10 \%$ level of significance with respect to implementing behavioral trainings. Also the mean value is maximum for the no. of clients $<5$ and decreases as the number of clients increases for both technical and behavioral trainings. This indicates that lower the number of clients, the difficulty is more to implement Virtual Trainings.

Result 13: There is no significant difference between the Technical and Behavioral implementation of Virtual Trainings with respect to number of branches.

Result 14: There is no significant difference between the Technical and Behavioral implementation of Virtual Trainings with respect to number of sectors.

Result 15: There is no significant difference between the Technical and Behavioral implementation of Virtual Trainings with respect to outsourcing activities.

Table 10: Represents the comparison of 8 P's of technical and behavioral means with each of the Factor variable namely No. of Branches.

\begin{tabular}{|l|l|l|l|l|l|l|l|l|}
\hline \multicolumn{1}{|c|}{ Variables } & \multicolumn{6}{|c|}{ Technical- No. of Branches } & \multirow{2}{*}{ F value } & \multicolumn{3}{|c|}{ Behavioural- No. of Branches } & F Value \\
\cline { 8 - 10 } & 1 & 2 & 3 & & 1 & 2 & 3 & \\
\hline People & 2.187 & 2.410 & 1.769 & 2.407 & 2.480 & 2.667 & 2.038 & 1.814 \\
\hline Product & 1.952 & 2.467 & 2.400 & 2.078 & 2.200 & 2.733 & 2.400 & 1.499 \\
\hline Place & 2.317 & 2.556 & 2.250 & 0.371 & 2.429 & 2.556 & 2.333 & 0.118 \\
\hline Process & 2.138 & 2.367 & 2.200 & 0.239 & 2.467 & 2.400 & 2.250 & 0.117 \\
\hline
\end{tabular}




\begin{tabular}{|l|l|l|l|l|l|l|l|l|} 
Price & 2.243 & 2.633 & 2.050 & 0.712 & 2.419 & 2.667 & 2.050 & 0.595 \\
\hline Promotion & 2.111 & 2.500 & 2.333 & 1.299 & 2.365 & 2.556 & 2.500 & 0.241 \\
\hline Productivity & 2.116 & 1.963 & 2.389 & 0.543 & 2.508 & 2.333 & 2.611 & 0.178 \\
\hline Physical Evidence & 2.114 & 2.600 & 2.300 & 0.77 & 2.610 & 2.600 & 2.200 & 0.303 \\
\hline
\end{tabular}

Result 16: There is no significant difference between the Technical and Behavioral implementation of Virtual Trainings for the 8 P's with respect to no. of branches.

Table 11: Represents the comparison of technical and behavioral means with each of the 8 P's for the Factor variable namely No. of Clients.

\begin{tabular}{|c|c|c|c|c|c|c|c|c|c|c|c|c|}
\hline Variables & \multicolumn{5}{|c|}{ Technical- No. of Clients } & F value & \multicolumn{5}{|c|}{ Behavioral- No. of Clients } & F Value \\
\hline & $<5$ & 5 to 10 & $\begin{array}{ll}10 & \text { to } \\
20 & \end{array}$ & $\begin{array}{ll}20 & \text { to } \\
40 & \end{array}$ & $>40$ & & $<5$ & 5 to 10 & $\begin{array}{ll}10 & \text { to } \\
20 & \end{array}$ & $\begin{array}{ll}20 & \text { to } \\
40 & \end{array}$ & $>40$ & \\
\hline People & 2.308 & 2.462 & 2.450 & 2.423 & 1.769 & $2.273^{8}$ & 2.308 & 2.865 & 2.303 & 2.500 & 2.077 & 2.042 \\
\hline Product & 2.800 & 2.550 & 2.150 & 2.100 & 1.600 & $3.053^{88}$ & 2.800 & 2.950 & 2.093 & 2.000 & 1.800 & $4.043^{88}$ \\
\hline Place & 3.333 & 2.708 & 2.067 & 2.417 & 2.000 & 3.69988 & 3.333 & 2.750 & 2.289 & 2.250 & 1.833 & 1.98 \\
\hline Process & 3.200 & 2.525 & 2.087 & 1.900 & 1.800 & $3.202^{88}$ & 3.200 & 2.825 & 2.413 & 1.700 & 1.600 & $2.84^{88}$ \\
\hline Price & 3.400 & 2.925 & 1.940 & 1.900 & 1.890 & $4.353^{888}$ & 3.400 & 3.000 & 2.107 & 2.100 & 2.100 & $2.775^{88}$ \\
\hline Promotion & 3.000 & 2.542 & 2.089 & 1.917 & 1.667 & $3.688^{88}$ & 3.000 & 2.750 & 2.444 & 1.833 & 1.500 & $4.203^{888}$ \\
\hline Productivity & 2.444 & 2.444 & 2.059 & 1.944 & 1.333 & 1.736 & 2.444 & 2.778 & 2.563 & 2.056 & 1.667 & 1.32 \\
\hline $\begin{array}{l}\text { Physical } \\
\text { Evidence }\end{array}$ & 3.400 & 2.550 & 2.080 & 2.000 & 1.400 & $2.222^{8}$ & 3.400 & 2.700 & 2.560 & 2.500 & 1.200 & 1.556 \\
\hline
\end{tabular}

(Level of Significance - '*' implies 10\%, '**' implies 5\% and ' ***' implies 1\%)

Result 17: With respect to the factor variable 'no. of clients' the Price variable seems to have the greatest mean and highest significance for Technical category. Similarly other all other P's except Productivity shows significance for No. of clients with respect to Technical category. For behavioral category Promotion is most significant followed by Product, Process and Price.

Table 12: Represents the comparison of 8 P's of technical and behavioral means with each of the Factor variable namely No. of Sectors.

\begin{tabular}{|l|l|l|l|l|l|l|l|l|l|l|l|l|}
\hline Variables & \multicolumn{4}{|l}{ Technical- No. of Sectors } & \multicolumn{2}{l|}{ F value } & \multicolumn{3}{l|}{ Behavioral- No. of Sectors } & \multicolumn{2}{l|}{ F Value } \\
\hline & 1 & 2 & 3 & 4 & 5 & & 1 & 2 & 3 & 4 & 5 & \\
\hline People & 2.54 & 2.4 & 2.04 & 1.74 & 1.46 & $5.403^{* * *}$ & 2.82 & 2.62 & 2.35 & 2.1 & 1.77 & $2.51^{*}$ \\
\hline Product & 2.47 & 2.2 & 1.95 & 2 & 1 & 1.501 & 2.67 & 2.24 & 2.4 & 2.27 & 1 & 1.482 \\
\hline Place & 2.28 & 2.43 & 2.5 & 2.33 & 1 & 1.354 & 2.39 & 2.33 & 2.67 & 2.56 & 1.33 & 0.887 \\
\hline Process & 2.6 & 2.06 & 2.23 & 2.13 & 1.1 & 1.283 & 2.77 & 2.3 & 2.53 & 2.4 & 1 & 1.164 \\
\hline Price & 2.4 & 2.08 & 2.73 & 2.17 & 1.1 & 1.367 & 2.4 & 2.14 & 3.05 & 2.3 & 1 & $2.415^{*}$ \\
\hline Promotion & 2.5 & 2.07 & 2.21 & 2.28 & 1.67 & 0.835 & 2.72 & 2.03 & 2.58 & 2.67 & 1.67 & $2.416^{*}$ \\
\hline Productivity & 2.3 & 1.98 & 2.17 & 2.22 & 1.56 & 0.468 & 2.7 & 2.36 & 2.5 & 2.63 & 1.56 & 0.607 \\
\hline $\begin{array}{l}\text { Physical } \\
\text { Evidence }\end{array}$ & 2.93 & 1.92 & 2.2 & 2.27 & 1.2 & 1.969 & 2.93 & 2.4 & 2.65 & 2.53 & 1.2 & 0.804 \\
\hline
\end{tabular}

(Level of Significance - '*' implies 10\%, '**' implies 5\% and ' $* * *$ ' implies 1\%)

Result 18: With respect to the factor variable 'no. of sectors' the People variable seems to have the greatest mean and highest significance for Technical category. Similarly all other P's except shows no significance for No. of sectors in Technical category. For behavioral category Promotion, Price and People are significant.

Table 13: Represents the comparison of 8 P's of technical and behavioral means with each of the Factor variable namely Outsourcing.

\begin{tabular}{|c|c|c|c|c|c|c|}
\hline \multirow[t]{2}{*}{ Variables } & \multicolumn{2}{|c|}{$\begin{array}{c}\text { Technical- Outsourcing } \\
\text { activities }\end{array}$} & \multirow[t]{2}{*}{ F value } & \multicolumn{2}{|c|}{$\begin{array}{c}\text { Behavioural- Outsourcing } \\
\text { Activities }\end{array}$} & \multirow[t]{2}{*}{ F Value } \\
\hline & Yes & No & & Yes & No & \\
\hline People & 2.11 & 2.32 & 1.43 & 2.39 & 2.6 & 1.04 \\
\hline Product & 1.97 & 2.4 & $3.19^{*}$ & 2.16 & 2.68 & $4.34 * *$ \\
\hline Place & 2.33 & 2.4 & 0.07 & 2.43 & 2.47 & 0.02 \\
\hline Process & 2.03 & 2.52 & $3.6^{*}$ & 2.26 & 2.78 & $3.03^{*}$ \\
\hline Price & 2.14 & 2.62 & 2.43 & 2.29 & 2.7 & 1.59 \\
\hline Promotion & 2.18 & 2.3 & 0.35 & 2.35 & 2.57 & 0.81 \\
\hline Productivity & 2.04 & 2.29 & 1.06 & 2.41 & 2.64 & 0.64 \\
\hline Physical Evidence & 2.04 & 2.64 & $3.73 *$ & 2.48 & 2.72 & 0.43 \\
\hline
\end{tabular}

(Level of Significance - '*' implies 10\%, '**' implies 5\% and ' $* * *$ ' implies 1\%)

Result 19: With respect to the factor variable 'outsourcing activities' the Product, Process and Physical Evidence variables seems to have significance for Technical category. Similarly for behavioral category Product and Process shows Significance in results. 


\section{Discussion}

It is evident from the Result 5 that there is significant difference in implementing the technical and behavioral category trainings with respect to Virtual Trainings because the technical trainings are more of the standard procedural types and the behavioral programs need more of people interaction which seems to be less in virtual mode of training. Therefore consultants encounter more difficulties while implementing behavioral Virtual Trainings. This has already been pointed out by (Robert W. Taylor, 2002) in his research.

Owing to the Result 6 , it is evident that consultants encounter more difficulties while implementing behavioral Virtual Trainings with respect to People, Product, Price, Promotion, Process, Productivity and Physical Evidence compared to technical Virtual Trainings implementation. Secondly, it is also inferred that since it is Virtual Training, there is no significant difference with respect to the 'Place' factor for Technical and Behavioral trainings. Thus place or commutation is the one convenient factor for the consultants and hence they are able to deliver the training irrespective of wherever the client is.

Result 7 indicates that there is significance difference with respect to pre and post training of behavioral category and not technical category because of the fact that the learning effectiveness, business impacts and other significant post training factors are easy to measure for Technical programs whereas it is difficult to interpret for behavioral trainings.

Result 8 indicates that the consultants face difficulties with respect to the product factor during the pretraining phase and the price factor during the post training phase with respect to behavioral and Technical categories. This is because, since the profit and ROI are not directly measurable by the client's side before the training and hence, pricing seems to be difficult for the post training phase. And since most the trainings require customized package and rarely the clients accept for a generalized package, product factor shows difficulty too. Apart from the above two factors, physical evidence (post training) factor and process (post training) factor shows high Significance $(1 \%)$ for behavioral trainings estimating the individual goals vs training goals synchronization for behavioral programs is difficult and similarly estimating the overall training experience for behavioral programs is also difficult. Apart from these two, the promotion aspect for behavioral program has also shown significance (5\%) because of the fact that technical programs have the business need and is easy to promote whereas in the case of behavioral programs, it is not the case as it is more of the individual oriented.

Result 9 indicates that there is no significant difference between technical and behavioral categories with respect to the ranking of 8 P's. Hence all the 8 P's are unique contributors to the implementation of technical and behavioral Virtual Training implementation.

Result 10 indicates that in common for both technical and behavioral programs, achieving uniform experience among all participants and determining the ROI and Profit for the consultancy is the most difficult with respect to Virtual Training implementation. Apart from that, incurring cost for updating technology periodically, keeping up the agenda and timing during delivery of training and handling the target audience at various hierarchical levels for technical programs were difficult for technical programs implementation. For behavioral program implementation, creating interests among participants to ensure next registration, getting the attention of the participants, estimating the overall training experience and identifying the gaps pertaining to the same are difficult. These are obvious difficulty variables because behavioral programs are more subjective in nature and immeasurable involving the involvement of audience.

Result 12 indicates that lower the number of clients, the difficulty is more to implement Virtual Trainings as the experience factor is also low and the demand will be less making the consultant meet the ends for them resulting in poor quality delivery.

Result 13 to Result 15 indicates that no significant difference between the Technical and Behavioral implementation of Virtual Trainings with respect to number of branches, number of sectors and outsourcing activities respectively. This is one of the benefits of Virtual Training wherein the number of branches or number of sectors does not matter. Virtual Trainings can be implemented anywhere and anytime irrespective of the location and number of participants associated. Also whether the tasks are outsourced or not outsourced does not make a big difference with respect to the implementation of the

Extending this to the 8 P's, Result 17 shows that the lesser the number of clients, the more difficult it is with respect to Promotion, Pricing, Process and Product for both technical and behavioral programs and the lesser the number of clients, even place, people and physical evidence are difficult for technical programs. Result 18 indicates that the lesser the number of sectors the more difficult it is with respect to the People aspect (fixing up audience and trainers) with respect to technical and behavioral trainings and in addition for behavioral training, even pricing and promotional activities will be difficult. Result 19 indicates that the more the consultants outsource their training activities, the more difficult it becomes for them with respect to delivering an efficient process and product for both technical and behavioral program delivery. In addition for technical programs, the physical evidence is also affected. 


\section{Conclusion}

Though the significance of Virtual Training has been realized by the IT companies, there still exist some major pitfalls with respect to getting the same effectively and efficiently delivered from the consultant's point of view. There has not been any significant study or research made in the angle of focusing on the pitfalls in implementation of Virtual Training and bridging the gap. This paper hence infers that it is more difficult to implement behavioral trainings than technical trainings when it comes to delivery through virtual mode. Hence to bridge this gap, modes like video conferencing (which is the most preferred as per Table 11) where two sides interaction with audio is available has to be used when delivering behavioral programs. Secondly, the post training interpretation activities like measuring the ROI, profit, business impact, learning effectiveness and ensuring that the feedback is measurable, suitable standard post training metric measurement tools like Gooddata (tool designed especially to measure online training effectiveness), Metrics that matter etc.. has to be used.

Thus Virtual Trainings can become easy to implement and also more profitable, and more focus is required with respect to promoting the same effectively and having more number of clients so that efficiency and effectiveness can be assured. Also, it is important that the consultants look into all possible business sectors like manufacturing, education, Govt and private sectors, Banking etc... wherever Virtual Training venture is possible. Also, when they restrict themselves in not outsourcing some of the major activities like requirement gathering, content development and trainers, their efficiency and effectiveness of training delivery would be high. This study focuses on the difficulties in implementation of Virtual Trainings in IT sector only and as we have already seen that the majority of consultants are into more than one sectors, it can be extended to other sectors also.

\section{References}

[1]. Arpan Kar (2011), '7 Ps, 8 Ps, Marketing mix, Services Marketing', Advertising \& Branding, Marketing, Marketing Theory, Sales \& Distribution

[2]. Cifuentes, L. S., Yu-Chih Doris. (2001). Teaching and Learning Online: A Collaborative Between U.S. and Taiwanese Students. Journal of Research on Computing in Education, Summer 2001; Vol 33(4), pp. 456.

[3]. Cushing Anderson, (2010), When, Why and What to Outsource', Chief Learning Officer magazine, Sep 2010, Pp: 54-56.

[4]. David I Lepak, Scott A. Snell and Shad S. Morris, (2005), 'An Architectural Approach to Managing Knowledge Stocks and Flows:Implications for Reinventing the HR Function', CAHRS Working Paper Series

[5]. K. Gurchiek, (2005), 'Record growth: I. Outsourcing of HR functions', HR Magazine Pp.35-36

[6]. James, Gary W., (2001) ,'Advantages and Disadvantages of Online Learning'. Retrieved October27,2001 from http://www.allencomm.com/pdfs/white papers/ad dis ol.pdf

[7]. Robert W. Taylor, (2002) "Pros and cons of online learning - a faculty perspective", Journal of European Industrial Training, Vol. 26 Iss: 1 , pp. $24-37$

[8]. Snell, S. A., Stueber, D. \& Lepak, D. P. (2001), 'Virtual HR Departments: Getting Out of the Middle' , CAHRS Working Paper Series

[9]. Taylor, S. (2002)., 'Education online: Off course or on track?' ,Community College Week, Vol. 14(Issue 20) 